\title{
Pupils or Prisoners? Institutional Geographies and Internal Exclusion in UK Secondary Schools
}

\author{
John Barker, Pam Alldred, Mike Watts and Hilary Dodman
}

\begin{abstract}
:
A growing interest in the geographies of schooling has led to an exploration of a variety of school spaces. An increasing number of secondary schools offer internal fixed-term exclusions so that temporary removal from school is not seen as "time off" for students. This particular strategy has led to the creation of a new type of space in schools. Drawing upon research undertaken in a London secondary school this paper explores the geography of these new secluded spaces. We highlight that the configuration of physical space in Seclusion Units, combined with the regulation of spatial practices, create highly controlled and segregated spaces of punishment. We explore the powerful transformative effects of these spaces to change students' behaviour, social interaction and attitudes to learning. However, rather than simply creating docile subjects, we recognise that domination is never complete and we explore the extent and the limit of student resistance to the discipline and control of the Seclusion Unit.
\end{abstract}

Keywords: School, young people, discipline, punishment, exclusion

\section{Introduction: Geographies of Schooling}

Although schools have often been sites of data collection, they have until recently received less attention from geographers than other institutional spaces. There is now a growing interest in the geographies of schooling (Collins and Coleman, 2008), recognizing schools are key spaces of childhood (Edwards and Alldred, 1999, Vanderbeck, 2005, Kraftl, 2006). Geographical debates around schooling have often drawn upon the institutional geographies literature. The work of Foucault $(1977,1980)$ has been valuable in mapping spatial practices in institutions such as prisons, workplaces, and psychiatric hospitals as well as schools. Foucault (1977) uses the term panopticism (which draws upon but is not limited to Bentham's $18^{\text {th }}$ Century architectural design of the Panopticon) to identify how specific spatial arrangements place subjects under constant surveillance or the constant possibility or threat of such (see also Sharp et al., 2000, Parr, 2000, Wainwright, 2005). The regulatory gaze and subtle and specific spatial arrangements create systems of power which transmit particular values and norms and enable the discipline, control and regulation of bodies, behaviour and identity. In doing so, these produce particular docile and reformed subjects (Philo and Parr, 2000).

This classic Panoptic gaze has been identified in classrooms and other school spaces. Regulation and control is achieved through actual surveillance or the possibility of such (Pike, 2008), as Catling (2005, p327) states "in the classroom, children become used to being watched and noticed, and fundamentally to know where control lies". Geographers and others have begun to map the physical design and organisation of space in schools, responding to Philo and Parr's call (2000) to map the geography and internal arrangement of space inside 
institutions. For example, researchers have mapped children's use of school playgrounds (Tranter and Malone, 2004, Thomson, 2005), school dining rooms (Pike, 2008), and the moral geographies of classrooms (Fielding, 2000, Catling, 2005).

Geographies of schooling has also drawn upon the geographies of children and youth, a rapidly expanding sub-discipline (Vanderbeck, 2008), which over the past decade has mapped a wide variety of everyday spaces of childhood across the globe, including schools (Holloway et al., 2000, Kraftl, 2006), the street (Matthews et al., 2000, Young and Barrett, 2001), nurseries (Gallacher, 2005) and intentional communities (Maxey, 2004). Schools are but one of many specialised adult-constructed and controlled institutions which place children in contained zones and structure their space and time (Smith and Barker, 2000, Holloway and Valentine, 2000, Thomas, 2000, Maxey, 2004). However, children do not passively accept adult regulation nor adult attempts to shape their knowledge, identities or behaviour. Rather, children are competent social actors who employ a variety of strategies to contest, challenge or to transgress adult spatial hegemony and boundaries (Valentine et al., 2000, Cahill, 2004) both in schools (see Fielding, 2000, Thomson, 2005, Catling, 2005) and elsewhere (Smith and Barker, 2000). Furthermore, different groups of young people may experience schooling in very diverse ways (for example, see Holt, 2007 on disabled children's experiences of schooling, and Vanderbeck, 2005, on traveller children and schooling). This paper responds to recent calls from children's geographers for more engagement with social theory and radical debate (see Horton and Kraftl, 2005 and Vanderbeck, 2008) through using a Foucauldian approach to surveillance to explore a new type of space in schools and to consider the extent and limit of children's agency in these settings.

\section{Internal Seclusion in Schools}

A fixed-term exclusion from school is a disciplinary measure which headteachers can use to deal with incidents of serious misbehaviour. In 2005/6, there were 343,840 non permanent fixed-term exclusions from schools in England (DfES, 2007). A fixed-term exclusion can last up to five days in any one period and places responsibility upon parents/ carers to ensure the young person is not present in a public place during normal school hours and that work sent home is completed and returned to school. In order that exclusion does not function as a reward ('time off school'), and in order that excluded students receive education and adequate supervision, a growing number of schools in the UK (though rarely elsewhere) have developed school-based internal exclusion, also known as Seclusion Units or remove rooms (DCFS, 2008). Seclusion Units have arisen from political pressure to raise educational standards and attainment, to reduce levels of exclusion from school and to remove the threat of "undesirable" young people using public space during school hours.

The UK government has no overall strategy or requirement for schools to develop Seclusion Units (indeed no central figures are available about their prevalence nor is there a prescribed 
model). Official guidance highlights that Seclusion Units commonly aim to punish disruptive behaviour, mediate between the school and parents, and offer clear and organised support for students' learning, for managed re-integration to mainstream classes and to secure improvements in students' behaviour (DCSF, 2008). Typically, students cannot socialise with friends, are closely supervised and taught intensely (on a staff student ratio approaching 1:1) and are therefore more, not less, focused on learning whilst excluded from the classroom. Whilst part of a broader approach to supporting students at risk of exclusion, Seclusion is distinct from existing support services such as Learning Support Units or In-School Centres (see McKeon, 2001, Hallam and Caste, 2001). Whilst access to many school support services may be through referrals, access to Seclusion is restricted to those who have been required to attend as punishment.

These new types of school spaces have been controversial, in that some discussions (for example, on UK television and on web-forums) have suggested that their highly punitive nature violates children's rights. Furthermore, their presence can be seen as an example of the inexorable rise of the surveillance society in the UK through a diverse number of strategies of surveillance in public and private spaces (Koskela, 2000, van Haven and Sibley, 2008), and in particular the policing and surveillance of young people (Matthews et al., 2000, Ansell, 2009). However, there is little research which considers the effectiveness of Seclusion Units (see McKeon, 2001, Hallam and Caste, 2001 as exceptions) or which explore young people's views of these spaces. This paper does not seek to provide a comprehensive evaluation of the efficacy of Seclusion. Rather, we demonstrate how this particular policy shift is significant as it has led to the creation of new types of spaces of punishment hitherto not seen in schools.

\section{About the research}

New Academy ${ }^{1}$, located in London, is one of a growing number of academy schools. This flagship government policy involves building new state schools using private sector sponsorship (up to $£ 2 \mathrm{~m}$ per school), in return for a significant degree of control over the school's curriculum, ethos and staffing. The school serves a predominantly socially disadvantaged community over a relatively confined local geographical area. Entitlement to free school meals is common and the proportion of students who have learning difficulties and/or disabilities is above average. Around three quarters (72\%) of students are of white British heritage whilst the proportion of students for whom English is an additional language is above average.

The Seclusion Unit opened in 2007, in response to concern over widespread poor behaviour and rising rates of fixed-term exclusions. The Unit is supervised by a higher level teaching

1 A pseudonym 
assistant (class teachers with free periods are also often allocated one half hour slot per week in the Unit). In its first year of operation, almost one quarter (22\%) of the student body were required to attend Seclusion. The main most often cited reasons for Seclusion were verbal abuse $(40 \%)$, persistent disruptive behaviour (19\%) and failure to follow instruction from staff $(18 \%)$. This paper is based on an evaluation undertaken by the authors and funded by the Academy ${ }^{2}$. The evaluation used two methods. A statistical analysis of the Unit's database (detailing for each Seclusion event the age, gender, ethnicity and year group of each student, the reason for Seclusion and length of stay) was undertaken to explore patterns of Seclusion. Secondly, a total of 29 in-depth individual and focus group interviews (involving 39 respondents) were undertaken, including interviews with a range of school staff (including the Principal, Assistant Principals, Head of Years, classroom teachers and learning assistants), parents and students, including those students who had and had not been Secluded. This was complemented by our informal observations during our weekly visits to the school over a six month period.

\section{The Geography of Seclusion}

Geographers have begun to map the organisation and physical design of space in schools (Fielding, 2000, Thomson, 2005, Kraftl, 2006, Collins and Coleman, 2008). Using contemporary approaches to design, New Academy is housed in a bright, transparent building. Classrooms and communal areas are spacious and flooded with light from floor to ceiling windows and glass roofs. The internal walls of each classroom are comprised, at least in part, of glass walls, so that students can look onto communal spaces such as corridors, the dinner hall and main reception, whilst also enabling staff in corridors to observe classrooms. One student identified this as part of a broader surveillance culture within the school:

The school's got more stricter (sic). (We are) being more watched, like, all the time... 'coz they have cameras everywhere, (the staff) walk around the corridors with walkie talkies. Male non-Secluded student

Schools have become increasingly sophisticated sites for surveillance. Recent advances in building design and materials, and contemporary building practices, have embraced and enhanced the potential for the panoptical disciplinary gaze in schools (see Pike, 2008). In contrast to the rest of the school, the Seclusion Unit is hidden and difficult to find (the door is euphemistically titled "Inclusion"). Unlike most other school spaces, the Unit is located behind heavy wooden doors which have only small glass panels, so there is no opportunity for passing students or staff to glimpse into the Seclusion Unit, clearly denoting the space as separate and isolated from the rest of the school. Separation is an often-used spatial tactic associated with punishment in other school spaces (see, for example, Thomson, 2005 on

2 We wish to express our thanks to the school for supporting the research. 
punishment in playgrounds). However, Seclusion is distinct from other punitive school-based segregation practices. Seclusion is longer lasting (operating the entire length of the school day) than other spatial practices of segregation young people are routinely subjected to in schools. Whilst visible demarcation of those punished is a routine spatial strategy with schools (for example, Pike, 2008 discusses the visible punishment of being forced to stand in the corner in school dinner rooms), Seclusion is not a highly visible spatial strategy of punishment, but one based on absence, physical isolation and separation from the rest of the school. The only exception to this was the limited number of occasions when Secluded students could be seen by other students:

If I do have to walk any of the (students in Seclusion) to the canteen or to the toilet, everybody's like, really interested. "Ooh, there's the Seclusion people", 'cos they like to jeer at them a little bit. Unit supervisor

This scene is reminiscent of Foucault's (1977) discussion of the Spectre of the Scaffold. Highly visible "ceremonies of punishment" (p49) re-enforce regulation and control and act as deterrent by displaying punishment. The school building's transparency, and the Secluded student's general departure from this, emphasises their position as Secluded. However, as the rest of the paper discusses, this very traditional and visible expression of power and control was rare in relation to the everyday practices associated with the Seclusion Unittactics and strategies of control were often much more subtle and invisible.

Time as well as space segregated Seclusion from the rest of the school. Institutions such as schools are highly regulated according to strictly defined timetables (Fielding, 2000). Of note here is that the Unit operated a timetable different to the rest of the school, a further punishment making it more difficult for Secluded students to socialise with friends at either end of the school day. Although the main timetable was not followed, the bleeping signals broadcast throughout the school to represent the end of each school period were heard in the Unit:

So they start here nine thirty-five, it's slightly different and at ten fifty-five it's break. So what is there? Two or three lesson but as I say, I don't keep to that. They may do two different subjects during that time and take a bit longer on them. Although we hear the bell going for the different lessons, no. I don't really put a time limit, I like to let them finish something. Unit supervisor

This particular strategy emphasises simultaneously that students are still subject to the school's regimes, whilst also highlighting separation, isolation and punishment. Similarly, specific spatial practices, acceptable in the rest of the school, were forbidden in the Unit:

You're not allowed to interact with other students... you just work on your own, you're not allowed to speak until break, there are boards in-between (desks) so you're not allowed to talk to other people while you're doing your work and stuff. Secluded male student 
These spatially-specific disciplinary practices (having to stay silent, remaining seated, including at break and lunchtime, and starting and finishing school at different times) were seen by students as punitive aspects of Seclusion and are indeed reminiscent of other spatial strategies employed in other institutional penal spaces (see, for example, Philo, 2001, van Hoven and Sibley, 2008). Indeed many students, parents and teachers said these spatial strategies and disciplinary tactics gave the Unit a 'prison-like' reputation:

Well a lot of them do say they feel that they're in prison. I explain to them it isn't a prison and the door isn't locked, as it would be in prison. But a lot of them say they feel as though this is what prison would feel like. Unit supervisor

They (students) do recognise it as form of punishment, I mean they'll go home and joke and say "gosh it's like being in prison". Teacher

Although more broadly Seclusion has become entangled in debates about children's rights, (questioning the legality and appropriateness of detaining young people in such penal spaces) this challenge to this new type of school space was noticeably absent in the respondents' accounts of Seclusion. Only one teacher (and none of the parents or students taking part in the research) mentioned such concerns:

For the first time yesterday I had a parent 'phoning up and saying "he's not going into that prison" Senior leadership team member

Therefore, the compulsive and penal nature of Seclusion was largely legitimised by parents and students as fair, appropriate and "deserved" punishment- as one student put it "a good punishment for bad behaviour." However, we need to recognise that simply because a dominant regime is powerful enough to reproduce itself as "legitimate" in the eyes of those subject to its control, does not necessarily mean that it is indeed legitimate or, in this case, free from scrutiny in relation to the UK's adherence to the United Nations (1989) Convention on the Rights of the Child.

As others have noted, the physical arrangement of classrooms matter (Catling, 2005). The physical space of the Seclusion Unit (see fig 1) is designed and organised in a very different way to the school's classrooms: 
Figure 1: Layout of the Seclusion Unit:

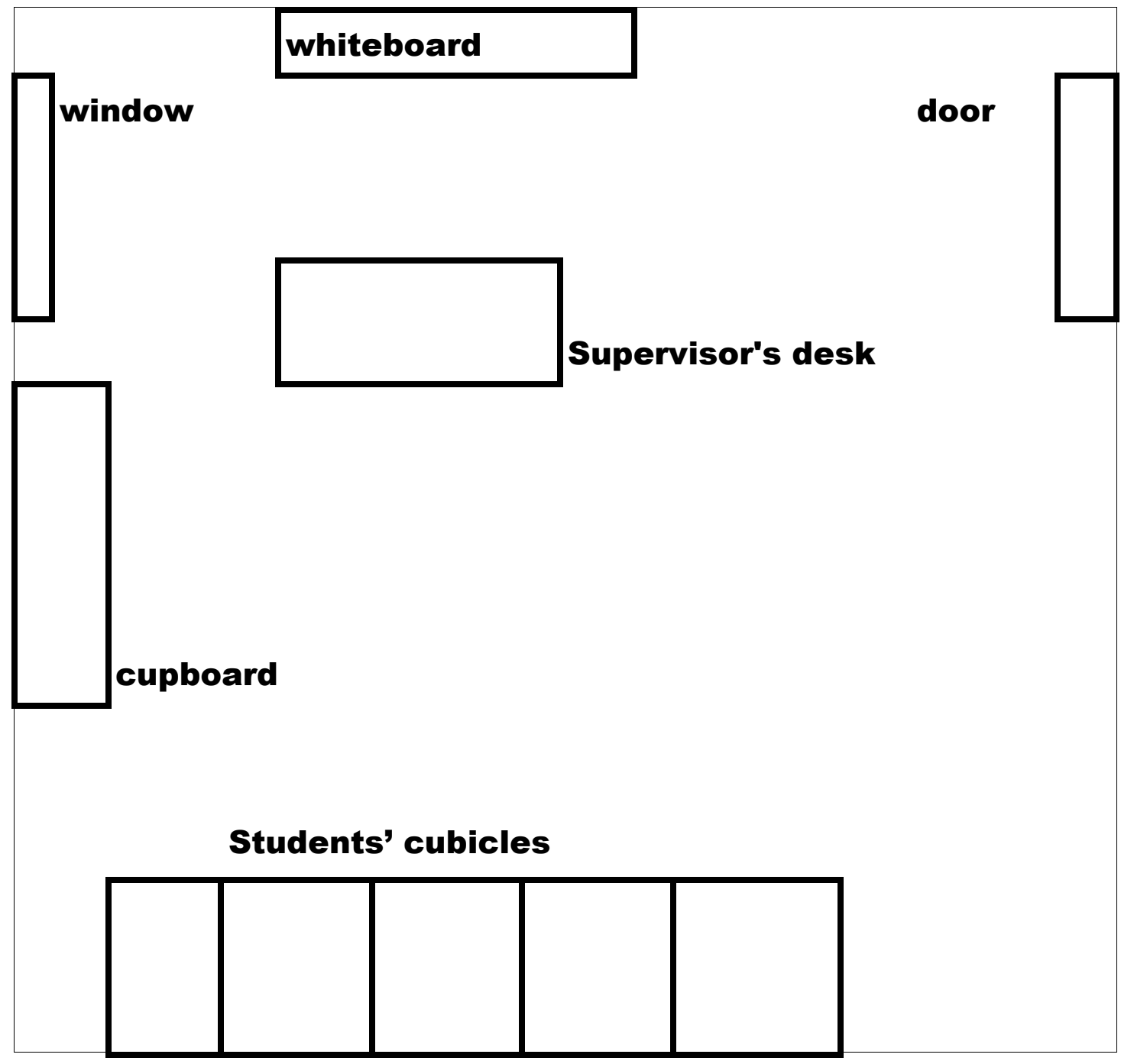

The school's classrooms are bright, spacious, equipped with wide benches positioned towards the front of the class, the teacher's desk and the interactive whiteboard. In contrast, the Seclusion Unit is a small room with a very small window. Instead of facing the front of the class, students sit in individual cubicles facing the wall, with the supervisor seated behind them, looking onto (and into) the cubicles:

...and they're made to face the wall, and we've put the barriers up to stop them communicating... Senior Leadership Team Member

It's just like walls where you're blocked off and you just have to sit there facing the wall. Male Secluded student

So they're away from the teacher, facing a wall with their desk. So they literally have a cubicle to work in and that's it. Senior Leadership Team Member

The physical configuration of space is not simply neutral, but signifies much to the subjects who inhabit it (Kraftl, 2006). The physical layout of Seclusion is clearly associated with 
punishment, mirroring the cells and partitioning found in prisons and other penal institutions (Foucault, 1977, Philo and Parr, 2000). Spatial arrangements and technologies produce a particular topography of power. The Seclusion Unit is organised to maximise the supervisor's view- a configuration which promotes regulation through visibility, as subjects are unrelentingly exposed to the gaze of others. Mirroring the classic Panoptic gaze, the layout of space is essential to these exercises of power and control (Philo and Parr, 2000, Wainwright, 2007, Pike, 2008). The surveillance within the Unit clearly links into different scalar strategies of surveillance of young people. The surveillance of young people in public and semi-public spaces (such as town centres and shopping malls) often challenges and problematises young people's presence (Mathews et al., 2000). Schools have multiple layers of surveillance (see also Kearns and Collins, 2003), and Seclusion Units is one powerful, small scale example of this. These scalar strategies are also intertwined, inform and support each other. Seclusion helps to prevent young people excluded from school from using public space. It is also interesting that with the advent of Seclusion Units, the meaning of exclusion has changed as exclusion from school now happens within school. These excluded young people remain the subject of surveillance and control of schools, even though they have been excluded from the everyday, mainstream spaces of schooling.

\section{Seclusion and reform}

The physical arrangement of space is not designed for its own sake, rather it is productive (Foucault, 1977). Spatial configurations (for example, in schools, prisons, hospitals and elsewhere) generate and produce particular subjects, influencing bodies, identities, attitudes and behaviours. Perhaps unsurprisingly, the physical arrangement of space in Seclusion and the regulation of specific spatial practices (combined with the ongoing threat of permanent exclusion) often influenced students' behaviour. Many teachers stated they were regularly surprised to see (often immediate) transformations in the behaviour of students attending the Unit:

Once they're there, I mean...Some of, particularly the girls, their character changes absolutely completely from being a sort of, you know loud mouth madams to "yes sir, please sir, three bags full, sir". It's as extreme as that. Senior leadership team member

You can spend all day working with them in here and by the end of the day, you've got somebody being really polite to you, doing work they didn't want to do. Unit supervisor

Reflecting what others have found, schools mould behaviour (Thomson, 2005) and the regulatory gaze (Vanderbeck, 2005) of Seclusion can produce behaviour very different to that seen in classrooms. Philo and Parr (2000) note there is a deliberate configuration of institutional spaces in order to produce more "docile" and "proper" subjects (also Birch et al., 2007, Collins and Coleman, 2008). As Foucault (1977) comments, the physical configuration of space is central to regulation and control, a point noted by one of the Seclusion staff: 
the teacher's behind them... I think, you know, almost by default that actually works rather nicely because it puts them in a frame of mind, they're not sitting in a class looking at the teacher because otherwise there would be constant interaction....if they need help, put their hand up sort of thing, they don't shout out. So, I'm very pleased that, if you like, the kids, almost change their demeanour when they go in there. I think the physical environment helps that as well and I'm quite pleased from that point of view. Senior Leadership Team member (emphasis added)

Whilst this creates docile subjects, it was clear that this was simultaneously both a result of children being moulded and manipulated, but also partly children's own active coping strategies to get through the day in Seclusion. As well as influencing behaviour, there was consensus amongst students and staff that students worked harder and achieved more in Seclusion than in class:

He does more work in there than in any of his classes. He does more in a day, than he does in a whole week. Parent of Secluded student

Work-wise, last time he was in there, one of the teachers who he doesn't get on with phones me up to tell me how outstanding he was in Seclusion. He said he couldn't believe he was reading his work, it was absolutely outstanding. Parent of Secluded student

Yeah [students do more work in Seclusion] because there's not like people distracting you... you're not talking to anyone. That [work] is the only thing to do.. so you're concentrating on your work more. Male Secluded student

One Senior staff noted that, upon reflection, students often surprise themselves by what they have achieved:

"I've never done this before, Sir", they say. Senior leadership team member

Sometimes at the end of the day, l've had kids come to me and show me work they have done in the room and be quite proud and pleased. It allows you to then say, "that's pretty good". Teacher

The accounts of and about Secluded students here are perhaps more reminiscent of "good learners" (see Fielding, 2000) than poorly behaved students at risk of permanent exclusion from school. Although there are extensive debates regarding effective education strategies (which are far reaching and beyond the scope of this paper), this evidence shows that the configuration of space and spatial practices in Seclusion, combined with the ongoing threat of permanent exclusion and the support of the Unit supervisor (to enable students to reflect on their actions and develop alternative strategies to support their learning) can produce significant changes in behaviour. This particular function reflects the broader reformatory aspect of other punitive institutions, to produce "decent" subjects. As Foucault comments:

"The panopticon was also a laboratory; it could be used as a machine to carry out experiments, to alter behaviour, to train or correct individuals". Foucault, 1977, p203 
However, attempts to reform Secluded students were often short term and partially successful at best:

It tends to have a temporary effect, with, I think the worst offenders, and a more lasting effect with those who don't really get into too much trouble Teacher

Indicating how space is deeply important and implicated in the constitution of the subject (Pike, 2008), many respondents noted that students reverted to their usual behaviour and attitudes to learning once they returned to everyday classrooms (complete with peer pressure, noise, different teacher-student ratios and differing styles and modes of teaching). Therefore the transformative effects of Seclusion were often limited to the space of Seclusioninterventions were not sufficient to enable long term behavioural changes amongst many Secluded students, or to address or resolve the complex behavioural issues or specific learning needs that many of them possessed.

\section{The possibilities and limits of resistance}

Just as space is actively organised to produce particular subjects, space is also important in enabling resistance (Thomson, 2005, Wainwright, 2007). There were a number of examples which showed that Secluded students were not simply passive individuals subjected to discipline, regulation and control. Two examples highlight this. Firstly, although partitions separating each desk were designed to isolate and separate students to prevent communication, this was often circumvented:

(I have to watch) the booths, obviously so that they cannot make any contact or communicate with anybody else. They do try to pass notes 'round the back. Unit supervisor

Another example involved the cupboard located against the wall, between the students' cubicles and supervisor's desk (see figure 1):

Sometimes if I'm helping one and I'm in the booth...you do need eyes in the back of your head in here because... any opportunity... looked away one day and one boy who was there was missing... And I thought, "well he can't have got past me out the door"... and he was in that cupboard. He was a six foot tall, lanky boy and he'd got himself in there and shut the door. It was quite comical really if you were allowed to laugh at it. I said to him "You ought to be in a circus". He was like a contortionist. So you need eyes in the back of your head. Unit supervisor

Whilst Foucault's panopticism (Foucault, 1977) suggests (at least in theory) a perfect exercise of power and offers little room for agency in the face of discipline and control, others have developed a more productive and positive conceptualisation of power, suggesting a more complex and nuanced picture of social and spatial relationships in institutions (Sharp et al., 2000, Philo and Parr, 2000, Wainwright, 2007). The examples here mirror those from other institutionalised populations (e.g. see van Hoven and Sibley, 2008) and show that where 
domination, discipline and control appear comprehensive, there are always possibilities (however mundane or inconsequential) for resistance, subversion and for using space in ways not intended or planned (Soja, 1996, Sharp et al., 2000).

An example of one Secluded student's behaviour illustrates the myriad of entangled power relations in which different individuals (including teachers as well as Secluded students) were placed, and how this simultaneously generated opportunities for domination and resistance:

I think when I'm in there [the Unit], I'm a little bit too confrontational. Because I did it [supervised the Unit]... on Tuesday and I could feel myself from time to time getting quite agitated, because she was... [loud tapping sound here to illustrate the student's tapping] Senior Leadership team member

\section{Oh right Interviewer}

I had to draw myself back from nagging if you like it, and then I sort of changed it to...(whispers here) "I would prefer if you didn't do that". "Sorry sir". And it was ok. Because my mind set is this-you don't even have a sound here.

The particular act of resistance (the student making loud tapping noises- a form of bodily resistance also identified in other institutional spaces, see Parr, 2000) generates a reaction from the teacher. However, in recognising that a loud remonstration with the student (which may well have been the usual strategy in a classroom) would be inappropriate in this particular space, the teacher's response is shaped and reconfigured by the particular space of the Seclusion Unit. This is reminiscent of the ways that nurses (as well as patients) and prison warders (as well as prisoners) are also caught in panoptic surveillance.

However, these examples of students' acts of resistance were limited in scope, often minor and inconsequential. These acts presented very limited opportunities for challenging the dominance of the Unit and for transformation. Despite their acts of transgression, students remained confined within the room and powerless to challenge in any meaningful sense the broader institutional structures and processes of surveillance and control. The examples therefore indicate the limits to agency, and that young people in such institutional settings are often less able to act (deliberately) on others or to transform space than they are acted upon by others (Ansell, 2009). Whilst this is so for many institutionalised populations, the status of the group under consideration (as aged under 16 and legally obliged to attend school) makes a difference here. Adults through their social status and institutional power located within the broader educational system are able to legitimise the control and containment of children (for example through these Seclusion Units) in ways which would be unacceptable for many other sections of the population.

\section{Conclusion}

This paper has mapped the entangled spatialities and power relations within these new 
spaces of punishment for young people. The physical configuration of Seclusion Units reenforce discipline and control, emphasise punishment and often create significant (if temporary) transformations in behaviour and attitudes to learning. However, these changes are mostly temporary and short lived, and students at risk of exclusion from school require substantive and ongoing support and intervention to help keep them in school and promote academic achievement.

The paper also responds to a recent call amongst children's geographers (see Horton and Kraftl, 2005, Vanderbeck, 2008) for a more thorough engagement with theory amongst children's geographers. Complementing the work which has focused on more everyday spaces of schools (Thomson, 2005, Catling, 2005, Holt, 2005) this paper shows the currency of a Foucauldian analysis in mapping new types of school spaces which have been established to punish poor behaviour. This approach to surveillance and power is useful in exploring both the extent of domination and the possibilities of resistance within institutional settings. Whilst the disciplinary gaze within Seclusion Units is highly powerful, the examples of students' transgressive acts suggest domination is not complete. However, that the transgressive acts are minor and often inconsequential indicate the limits of children's agency and the power and surveillance that is routinely enacted upon them.

Much of the configuration of space and the spatial practices identified within Seclusion echoes with research exploring other penal spaces in which adults spend their time, such as prison geographies (Philo, 2001) and other institutional geographies. Whilst this paper has considered students' experiences of one particular space of punishment, we call for more work to explore children and young people's perceptions of other less ordinary, less routine institutional (and penal) spaces such as young offenders' units and psychiatric hospitals. Furthermore, this paper hopes to generate moral debate about the desirability of these contemporary educational practices. An increasing number of schools provide highly restrictive spaces of punishment (in which young people's experiences mirror those of adults incarcerated in institutional settings) which are placed cheek by jowl with, although highly segregated from, everyday spaces of schooling.

\section{Acknowledgements}

We wish to thank the two anonymous referees and Emma Wainwright for their insightful, inspiring and helpful comments on earlier drafts of this paper.

\section{References}

Ansell N 2009 Childhood and the politics of scale: descaling children's geographies? Progress in Human Geography 33(2) 190-209

Birch J, Cyrtis P and James A 2007 Sense and sensibilities: In search of the child-friendly hospital Built Environment 33 (4) p405-16 
Cahill C 2004 Defying gravity: Raising consciousness through collective research Children's Geographies 2(2) 273-286

Catling S 2005 Children's personal geographies and the English Primary school geography curriculum Children's Geographies 3(3) 325-44

Collins D and Coleman T 2008 Social geographies of education: Looking within, and beyond school boundaries Geography Compass 2 (1) 281-99

DCSF 2008 Internal Exclusion Guidance http://www.teachernet.gov.uk/ doc/12506/Internal\%20Exclusion.pdf

DfES 2003 Behaviour and Attendance: In-depth audit for secondary and middle schools. Booklet 3: Dealing with Consistently Poor Behaviour http://www.standards.dfes.gov.uk/secondary/keystage3/downloads/ba indepthaudit020703bk 03.pdf

DfES 2007 Permanent and Fixed Period Exclusions from Schools in England 2006/07: http://www.dcsf.gov.uk/rsgateway/DB/SFR/s000793/index.shtml

Edwards R and Alldred P 1999 Children and young people's view of social research: The case of home school relations Childhood 6(2) 261-81

Fielding S 2000 Walk on the left: Children's geographies and the primary school, in Holloway, S and Valentine G (eds) Children's Geographies: Living, Playing, Learning 230-44

Foucault M 1980 Questions on geography, in Foucault M Power/ Knowledge: Selected Interviews and other Writings 1972-1977 Hemel Hempstead: Harvester Wheatsheaf 63-77

Foucault M 1977 Discipline and Punish: The Birth of the Prison London: Penguin

Gallacher L 2005 'The terrible twos': Gaining control in the nursery Children's Geographies 3(2) 243-264

Hallam S and Castle F 2001 Exclusion from school: What can help prevent it? Educational Review 53 (2) 169-179

Holloway S and Valentine G 2000 Children's geographies and the new social studies of childhood, in Holloway S and Valentine G (eds) Children's Geographies: Playing, Living, Learning London: Routledge 1-28

Holloway S, Valentine G and Bingham N 2000 Institutionalising technologies; Masculinities, femininities, and the heterosexual economy of the IT classroom Environment and Planning $A$ 32 617-633

Holmes D 2001 From iron gaze to nursing care: mental health nursing in the era of panopticism Journal of Psychiatric and Mental Health Nursing 8 7-15

Holt L 2007 Children's socio-spatial (re)production of disability within primary school playgrounds Environment and Planning D: Society and Space 25 783-802

Horton J and Kraftl P 2005 For more-than-usefulness: Six overlapping points about ehildren's geographies Children's Geographies 3(2) 131-143

Kearns R and Collins D 2003 Crossing roads, crossing boundaries: Autonomy, authority and risk in a child pedestrian safety initiative Space and Polity 7(2) 193-212

Koskela H 2000 'The gaze without eyes': video-surveillance and the changing nature of urban space Progress in Human Geography 24(2) p243-265 
Kraftl P 2006 Building an idea: The material construction of an ideal childhood Transactions of the Institute of British Geographers 31 (4) 488-504

Matthews H, Limb M and Taylor M 2000 The "street as thirdspace", in Holloway S and Valentine G (eds) Children's Geographies: Playing, Living, Learning London: Routledge 6379

Maxey L 2004 The participation of younger people within intentional communities: evidence from two case studies Children's Geographies 2(1) 29-48

McKeon M 2001 Promoting the inclusion of students at risk of exclusion: An evaluative case study Emotional and Behavioural Difficulties 6(4) 236-50

Parr H 2000 Interpreting the hidden social geographies of mental health, ethnographies of inclusion and exclusion in semi-institutional places Health and Place 6 225-237

Philo C 2001 Accumulating populations: Bodies, institutions and space International Journal of Population Geography 7 473-490

Philo C and Parr H 2000 Editorial: Institutional geographies: Introductory remarks Geoforum, 31 513-21

Pike J 2008 Foucault, space and primary school dining rooms Children's Geographies 6(4) 413-422

Sharp J, Routledge P, Philo C and Paddison R 2000 Entanglements of power: geographies of domination/ resistance, in Sharp J, Routledge P, Philo C and Paddison R (eds) Entanglements of Power: Geographies of Domination/ Resistance London: Routledge 1-42

Smith F and Barker J 2000 Contested spaces: Children's experiences of out of school care in England and Wales Childhood 7(3) 315-333

Soja E 1996 Thirdspace Oxford: Blackwell

Thomas M 2000 Guest editorial: From crib to campus: Kids' sexual/ gender identities and institutional space Environment and Planning A 32 577-580

Thomson S 2005 Territorialising the primary school playground: Deconstructing the geography of playtime Children's Geographies 3(1) 63-78

Tranter P and Malone K 2004 Geographies of environmental learning: An exploration of children's use of school grounds Children's Geographies 2(1) 131-156

Valentine G 1997 "Oh yes I can" "Oh no you can't": Children and parents' understandings of kids' competence to negotiate public space safely Antipode 29(1) 65-89

Valentine G, Holloway S and Bingham N 2000 Transforming cyberspace: children's interventions in the new public sphere, in: Holloway $S$ and Valentine $G$ (eds) Children's Geographies: Playing, Living, Learning London: Routledge 156-173

Van Hoven B and Sibley D 2008 'Just duck': the role of vision in the production of prison spaces Environment and Planning D: Society and Space 26 1001-17

Vanderbeck R 2005 Anti-nomadism, institutions and the geographies of childhood Environment and Planning D: Society and Space 23 71-94

Vanderbeck R 2008 Reaching critical mass? Theory, politics, and the culture of debate in children's geographies Area 40(3) 393-400 
Wainwright E 2005 Dundee's jute mills and factories: Spaces of production, surveillance and discipline Scottish Geographical Journal 121(2) 121-140

Wainwright E 2007 Detailing spaces and processes of resistance: Working women and Dundee's jute industry Geoforum 38 688-697

Young L and Barrett $\mathrm{H} 2001$ Issues of access and identity: Adapting research methods with Kampala street children Childhood 8(3) 383-395 